\title{
Erratum: Noise benefit in prepulse inhibition of the acoustic startle reflex
}

\author{
Erik Pålsson • Göran Söderlund • Daniel Klamer • \\ Filip Bergquist
}

Published online: 22 December 2010

(C) Springer-Verlag 2010

\section{Erratum to: Psychopharmacology}

\section{DOI 10.1007/s00213-010-2074-6}

The author wishes to apologize for inadvertently providing the wrong image for Fig. 4. Here is the correct image:
The online version of the original article can be found at http://dx.doi. org/10.1007/s00213-010-2074-6.

\section{E. Pålsson · D. Klamer}

Department of Pharmacology,

Institute of Neuroscience and Physiology, The Sahlgrenska Academy,

University of Gothenburg,

Box 400, 40530 Gothenburg, Sweden

\section{G. Söderlund}

Department of Linguistics, Stockholm University,

10691 Stockholm, Sweden

\section{F. Bergquist $(\bowtie)$}

Clinical Neuroscience and Rehabiliation, Institute of Neuroscience and Physiology,

The Sahlgrenska Academy, University of Gothenburg,

Box 400, 40530 Gothenburg, Sweden

e-mail: filip.bergquist@gu.se
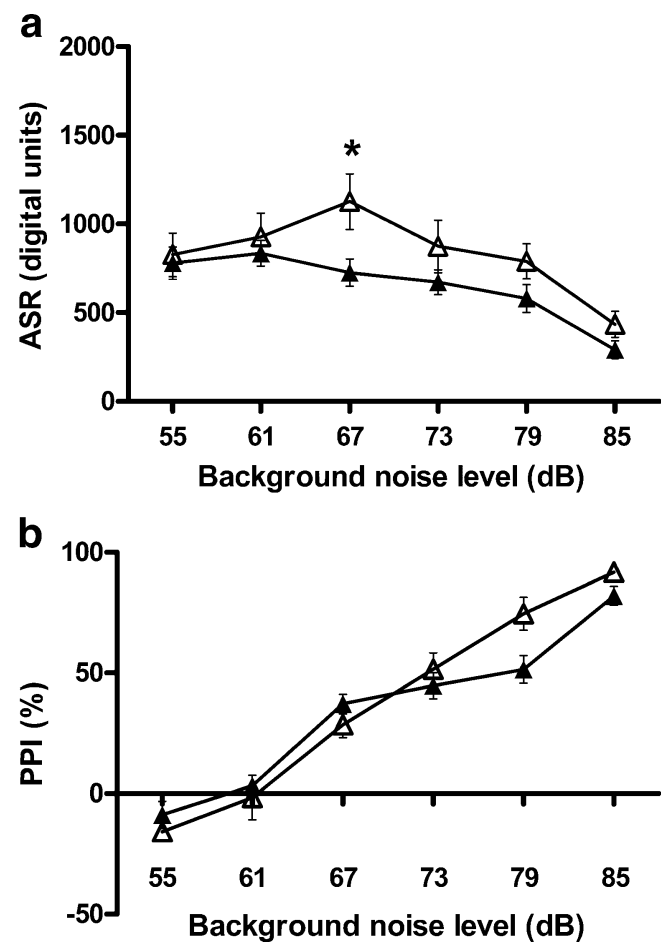

Fig. 4 a ASR to a single pulse expressed as digital units (mean \pm SEM) at different acoustic background noises in 6-OHDA-lesioned SpragueDawley rats. Responses are compared with intact Sprague-Dawley rats. Two-way ANOVA did not indicate a significant effect of 6-OHDA lesioning $F(1,100)=2.157, p=0.1575$, but significant effect of noise $F(5,100)=27.3$ and interaction lesion $\times$ noise $F(5,100)=2.546$, $p=0.0326$. Significant differences in Bonferroni-corrected post hoc $t$ tests indicated by a single asterisk $p<0.05$. b PPI of the startle response expressed as percent (mean \pm SEM) of startle response. Two-way ANOVA indicated a main effect of background noise level, $F(5,100)=75.34$, $p<0.0001$, but not of lesion treatment $F(1,100)=0.7398, p=0.3999$ or interaction lesion $\times$ noise $F(5,100)=2.035, p=0.0801$ 